\title{
The Effects of Agricultural Experience Program on Agricultural Literacy and Hand Function Improvement of Adolescents Living in Self-reliance Residence Hall
}

\author{
Ja Yeong Ryu ${ }^{1}$, Mi Jin Kim², and Suk Young Yun² ${ }^{2 *}$ \\ ${ }^{1}$ Doctoral student, Department of Horticulture, The Graduate School, Daegu Catholic University. Gyeongsan 38430, South Korea \\ ${ }^{2}$ Professor, Department of Horticulture, Daegu Catholic University, Gyeongsan 38430, South Korea
}

\section{ABSTRACT}

Background and objective: This study was conducted to increase understanding of agriculture through agricultural experience programs for adolescents living in self-reliance residence hall, and to investigate changes in work performance ability through changes in hand function.

Methods: There were 11 subjects, and the average age was 18.2 years, all males without disabilities. The agricultural experience program consists of a total of 10 sessions including orientation and watching videos on future agriculture, creating vegetable gardens, planting, managing each crop, harvesting, visiting the processing room, and selling at a local food store.

Results: The change in agricultural literacy by the agricultural experience program positively improved from a score of 113.73 to $127.91(p=.008)$. The changes by sub-item are as follows. The value and safety of agri-foods $(p=.020)$ and agriculture and natural environment $(p=.007)$ were significantly improved. The function and value of rural areas $(p=.050)$, production of agricultural products $(p=.160)$, processing and distribution of agricultural products $(p=.248)$, and agricultural policies $(p=.058)$ were not significantly changed. The simple function of the hands was measured by the number of pegs inserted during 30 seconds, and the assembly function was measured by the number of pegs inserted during 60 seconds. In the case of simple function, the dominant hand was improved from 14.82 to $15.83(p=.014)$, andthe non-dominant hand was also significantly improved from 13.79 to $15.01(p=.002)$. There was no significant improvement in the simple function $(p=.153)$ and assembly function $(p=.770)$ of both hands.

Conclusion: It is considered that the agricultural experience program will enable youths living in self-reliance residence halls to enhance their understanding of agriculture as an occupation, and enable them to play a role as wise consumers by positively affecting improvements in their agricultural literacy and simple hand functions.

Keywords: agri-foods, dominant hand, natural environment, Purdue pegboard

\section{Introduction}

Adolescence is a period of rapid physical development and many emotional changes. Youths can easily get agitated during this period due to such characteristics, and often engage in misconduct as a result of feelings of anxiety about an uncertain future (Shin, 2013). In particular, lack of parental love and interest can act as an important factor in driving juvenile delinquency (Yun, 2011). If developmental tasks are not achieved under such circumstances, young people may not adapt to society and become maladjusted even when they become adults (Kwon et al., 2012).

From a life-span developmental perspective, adolescence is an important period in which one's own aptitudes and

This paper was funded by the research funds of Daegu Catholic University in 2020.

Received: February 20, 2021, Revised: March 5, 2021, Accepted: April 30, 2021

First author: Ja Yeong Ryu, rjy3535@naver.com, (D) https://orcid.org/0000-0001-9678-7642

*Corresponding author. Suk Young Yun, yune1004@cu.ac.kr, (1) https://orcid.org/0000-0002-5862-0021 
abilities are found, and thereby one's identity is established (Lee, 2019). For the purpose of protecting adolescents who are exposed to misconduct or are not protected by their parents during such an important period, the Korean government has established self-reliance residence halls in accordance with the Act on the Treatment of Protected Juveniles, etc. to support youths in need of protection. Admission to self-reliance residence halls is for youths aged 12 to 24 who are willing to be self-supporting or those in need of protection. Youths who fall under the following categories are eligible for placement in self-reliance halls: those who have no place to reside after being discharged from a juvenile reformatory, juvenile training school graduates, criminal adolescents placed under probation, those who are recommended by a juvenile protection agency, or those who are unable to receive parental protection due impoverished circumstances and have difficulty making a living; and those from low-income families or who are eligible for National Basic Livelihood Security System (NBLSS) grants (Cho, 2017). Adolescents who committed crimes have difficulties in finding a job due to social prejudice; and work as day laborers or temporary employees due to poor academic background or dropping-out-of-school; and thereby are socially alienated and often relapse into crime (Jang, 2008). Career guidance programs and vocational training are positive variables that stop juvenile delinquency (Cho, 2013) and through independent living experience programs, the youths in child residential care experience an independent life in various areas and are trained to develop their capacity to prepare for independent living after termination of such institutional care (Kim, 2019).

As adolescence is a period when adolescents perceive the importance of and explore their careers, and the perceptions and images formed during this period can influence their career choices in the future, agricultural education in adolescence is important to build adolescents' positive perception of agriculture and explore various agricultural-related career paths (Jung et al, 2019). The urban agricultural experience activities of adolescents had the effect of improving feelings of helplessness, unstable states of mind, passive interpersonal relationships, and immature attitudes (Jung et al, 2016), and those who have formed a basic awareness of agriculture and experienced firsthand agricul- tural activities before adolescence are more likely to engage in stable farming activities (Oh and Kim, 2002). Education is the most direct means in which adolescents experience agriculture and rural areas, and cultivate attitudes to have an awareness of these things, but such education is mostly conducted in the field of school education (Park et al., 2019), so adolescents taken into care in self-reliance residence halls, who have left school, are unable to obtain such educational opportunities. In addition, the agricultural experience activities conducted for delinquent youths and at-risk youths not only provided them with opportunities to acquire agricultural skills, but also had the effect of solving social problems by promoting a spirit of cooperation and sense of responsibility (Lowson and Marcia, 1995).

Therefore, with the aim of giving adolescents residing in self-reliance residence halls an opportunity to choose agriculture as a profession, this study was conducted to increase their understanding of agriculture through agricultural experience programs, and examine changes of hand function to determine the effect of the agricultural experience program on their work performance.

\section{Research Methods}

\section{Subjects}

This study was conducted with regard to 14 adolescents among the adolescents admitted to a self-reliance residence hall in D city, who agreed in writing to participate in the study after being provided with a sufficient explanation of the purpose, method and period of the study. During the period, 3 subjects among the group left the hall, and the final subjects were 11, with an average age of 18.2 years. All were male adolescents without disabilities. According to a preliminary survey of agricultural experience, 2 subjects $(18.2 \%)$ had agricultural experience and $9(81.8 \%)$ had no experience.

\section{Methods}

\section{Program design}

It was found that the agricultural experience program 
Table 1. Agricultural experience program conducted in this study

\begin{tabular}{ccll}
\hline \multirow{2}{*}{ No. } & Date & \multicolumn{1}{c}{ Agricultural experience program } \\
\cline { 3 - 4 } & & \multicolumn{1}{c}{ Morning (10:00 - 12:00) } & \multicolumn{1}{c}{ Afternoon (13:00 - 14:00) } \\
\hline 1 & 8, May & Orientation and pre-test & Watching a video on future agriculture \\
2 & 15, May & Seeding and planting & Installing garden fence \\
3 & 22, May & Setting up the support & Touring the jujube processing room \\
4 & 25, May & Making a herb garden & Planting herbs \\
5 & 1, June & Weed control and cultivation & Training the stems of cucumber and pumpkin \\
6 & 8, June & Weed control and cultivation & Fertilizing \\
7 & 15, June & Weed control and cultivation & Harvesting cucumbers \\
8 & 22, June & Making a succulent plant garden & Harvesting pumpkins and eggplants \\
9 & 29, June & Learning the distribution of agricultural products & Learning how to deliver local food \\
10 & 6, July & Learning about the prospects of agriculture & Post-test and presentation \\
\hline
\end{tabular}

Table 2. The name of the crops used in the program

\begin{tabular}{cl}
\hline Classification & \multicolumn{1}{c}{ Scientific name } \\
\hline Fruit vegetables & $\begin{array}{l}\text { Capsicum annum, Lycopersicon esculentum, Solanum lycopersicum var. rasiforme, Citrullus vulgaris, } \\
\text { Cucucrbita spp. Cucumis sativus, Solanum melongena, Zea mays }\end{array}$ \\
\hline Leafy vegetables & Allium tuberosum, Brassica capitata, B. juncea, B. oleracea, B. rapa, Lactuca sativa \\
\hline Herb & $\begin{array}{l}\text { Mentha species, Salvia officinalis, Rosmarinus officinalis, Ocimum basilicum, Lavandula species, } \\
\text { Thymus vulgaris, Mentha piperita }\end{array}$ \\
\hline
\end{tabular}

helped adolescents learn more about the profession of agriculture, and that urban farming experience activities helped mitigate their problem behaviors (Jung et al., 2016). Based on the program of Jung et al. (2016), we designed a program that can be actually executed on a farm (Table 1). The program consisted of a total of 10 sessions, including orientation and watching videos on future agriculture, creating vegetable gardens, visiting the processing room, seeding and planting a variety of crops, managing each crop, harvesting, selling local food, and presenting their impressions and engaging in discussions, which enabled the subjects to have an overall agricultural experience from production to distribution.

Among the crops selected were leafy vegetables, fruits, and herbs with good decorative value, which are relatively quick and easy to cultivate, and usually used as food ingredients, so that the subjects could enjoy the joy of harvesting (Table 2).

\section{Program implementation}

The program was conducted at Farm B in K City, which practices social agriculture tasks designated by the Ministry of Agriculture, Food and Rural Affairs: once a week for 3 hours a day ( 2 hours in the morning and 1 hour in the afternoon) from May 8 to July 6, 2020.

\section{Evaluation tool}

\section{(1) Agricultural literacy}

Agricultural literacy refers to basic knowledge and understanding of agriculture that promotes sensible consumption activities in daily life and correct judgment on national policy by synthesizing, analyzing, and exchanging basic information on agriculture (Heo and Jung, 2008). In this study, since adolescents in self-reliance residence halls often have low levels of educational attainment due to dropping out of school, the evaluation survey form for elementary school students developed by Jeon (2015) was used in consideration of the level of knowledge of the subjects. The evaluation items consisted of a total of 32 questions: 8 questions on function and value of rural areas, 4 on agricultural product production, 4 on processing and distribution of agricultural products, 5 on the value and safety of agri-food, 
6 on agriculture and the natural environment, and 5 on agricultural policies. The evaluation was based on a 5-point Likert scale, and the higher the score, the higher the level of agricultural literacy. The evaluation survey of agricultural literacy was performed before the implementation of the program and after the completion of all 10 sessions. The survey of agricultural literacy used in this study was found to be very reliable: Cronbach's $\alpha=.969$.

\section{(2) Purde Pegboard}

The Purdue Pegboard (Model 32025, Lafayette Instrument ${ }^{\circledR}$, USA) test is a tool that focuses on upper limbs' functional training, coordination, and sense of space, and can be used to improve cognitive ability, and has been used extensively for the purpose of selecting employees who can perform jobs that require agility and coordination (Shin, 2008). It evaluates large-scale movement of the hand and arm and agility of the hand by measuring speed and accuracy through three movements of pinching, handling, and placing small pegs in a hole (Choi et al., 2016). As the Purdue Pegboard test can be performed on children over 5 years of age and adults, it has been used in various fields of research to quantify changes in hand function, including the study on the effect of hand function build-up training in college students on hand dexterity (Jang et al., 2016), and using as a tool to test the improvement of hand function in paralyzed patients (Shin, 2008). In general, changes in hand function can be quantified by measuring the change in time to perform a task with a set number of pegs or by measuring the number of pegs utilized to perform a task during a specified time. In this study, as in the study of Jang et al. (2016), the change in the number of pegs assembled in a limited time was measured. The simple functions of the dominant hand, non-dominant hand, and both hands were measured with the change in the number of pegs operated for 30 seconds, and the assembly function was measured with the change in the number of pegs assembled for 60 seconds (Jang et al., 2016). Those two sub-areas were measured before and after the program to quantify the effect of agricultural experience activities on the ability to perform jobs.

\section{Data analysis}

The collected data were analyzed after statistical processing using the SPSS Statistics software (Ver.19, IBM ${ }^{\circledR}$, USA). Cronbach's $\alpha$ coefficient was used as a method of evaluating the internal reliability of the evaluation survey form for agricultural literacy, and the Shapiro-wilk test was used to analyze whether the measured sample data followed a normal distribution. Since agricultural literacy does not follow a normal distribution $(p=.031)$, the change in agricultural literacy according to agricultural experience activities was analyzed by the Wilcoxon singed-rank test, a non-parametric method. Regarding the hand functions analyzed by the Shapiro-wilk test, $p=.756$ for the simple function and $p=.581$ for the assembly function, presenting a normal distribution. Therefore, the change in hand function after the subjects' agricultural experience activities was analyzed using matched samples t-test.

\section{Results and Discussion}

\section{Difference in mean before and after the program}

\section{Changes in agricultural literacy}

Overall, the change in agricultural literacy through the agricultural experience program was significantly improved from 113.73 points to 127.91 points $(p=.008)$. For the change in each item, significant improvement was shown in the value and safety of agri-food $(p=.020)$, agriculture and natural environment $(p=.007)$; there was no statistical significance in function and value of rural areas $(p=.050)$, production of agricultural products $(p=.160)$, processing and distribution of agricultural products $(p=.248)$, and agricultural policies $(p=.058)$ (Table 3$)$. Through the agricultural experience program including creating vegetable gardens, planting various crops, supporting climbing and vining crops according to the growing speed, fertilization, weed management, and selling directly to local food vendors after harvesting, it was found that the subjects improved in the items such as the value and safety of agri-food, agriculture and natural environment among the sub-items of agricultural literacy. 
Table 3. Changes in agricultural literacy before and after agricultural experience program (unit: score)

\begin{tabular}{|c|c|c|c|c|c|}
\hline \multirow{2}{*}{ Items } & \multirow{2}{*}{$\begin{array}{l}\text { No. of } \\
\text { items }\end{array}$} & \multirow{2}{*}{$\begin{array}{c}\text { Before } \\
\text { Mean } \pm \text { SD }\end{array}$} & \multirow{2}{*}{$\begin{array}{c}\text { After } \\
\text { Mean } \pm \text { SD }\end{array}$} & \multirow{2}{*}{$\mathrm{z}$} & \multirow{2}{*}{$p$} \\
\hline & & & & & \\
\hline Function and value of rural areas & 8 & $27.28 \pm 5.53$ & $30.36 \pm 5.12$ & -1.960 & $.050^{\mathrm{NS}}$ \\
\hline Production of agricultural products & 4 & $14.10 \pm 3.42$ & $15.19 \pm 3.57$ & -1.404 & $.160^{\mathrm{NS}}$ \\
\hline Processing and distribution of agricultural products & 4 & $14.28 \pm 3.07$ & $15.10 \pm 3.08$ & -1.156 & $.248^{\mathrm{NS}}$ \\
\hline Value and safety of agri-foods & 5 & $18.10 \pm 4.13$ & $20.73 \pm 3.74$ & -2.325 & $.020^{*}$ \\
\hline Agriculture and natural environment & 6 & $22.00 \pm 4.34$ & $25.55 \pm 4.44$ & -2.677 & $.007^{* *}$ \\
\hline Agricultural policies & 5 & $18.00 \pm 3.41$ & $21.00 \pm 2.90$ & -1.895 & $.058^{\mathrm{NS}}$ \\
\hline Total & 32 & $113.73 \pm 20.21$ & $127.91 \pm 14.47$ & -2.668 & $.008^{* *}$ \\
\hline
\end{tabular}

${ }^{\mathrm{NS}}$ Non significant and significant at ${ }^{*} p<.05,{ }^{* *} p<.01$ by Wilcoxon singed-rank-test.

Table 4. Changes in vocational ability before and after the agricultural experience program (unit: No. of pins)

\begin{tabular}{|c|c|c|c|c|c|}
\hline \multirow{2}{*}{ Function } & \multirow{2}{*}{ Useful hands } & Before & After & \multirow{2}{*}{$\mathrm{t}$} & \multirow{2}{*}{$p$} \\
\hline & & Mean \pm SD & Mean \pm SD & & \\
\hline \multirow{3}{*}{ Simple } & Dominant hand & $14.82 \pm 0.95$ & $15.83 \pm 1.91$ & -2.962 & $.014^{*}$ \\
\hline & Non-dominant hand & $13.79 \pm 1.40$ & $15.01 \pm 1.63$ & -4.030 & $.002^{* *}$ \\
\hline & Both hands & $22.15 \pm 4.54$ & $23.29 \pm 5.63$ & -1.547 & $.153^{\mathrm{NS}}$ \\
\hline Assembly & Both hands & $24.19 \pm 2.69$ & $24.65 \pm 6.55$ & -.300 & $.770^{\mathrm{NS}}$ \\
\hline
\end{tabular}

${ }^{\text {NS Non significant and significant at }}{ }^{*} p<.05,{ }^{* *} p<.01$ by paired t-test.

\section{Changes in vocational ability}

As a result of testing the hand function using a Purdue Pegboard to examine the change in vocational ability through the agricultural experience program, in the case of the simple function, the dominant hand was improved from 14.82 to 15.83 pins ( $p=.014$ ), and the non-dominant hand was also significantly improved from 13.79 to 15.01 pins $(p=.014)$. The simple function $(p=.153)$ and assembly function ( $p=.770$ ) of both hands were not statistically significant (Table 4).

The results of analyzing the impact of agricultural experience programs on agricultural literacy and vocational ability of adolescents residing in a self-reliance residence hall are summarized as follows. The agricultural experience program had a positive effect on the entire field of their agricultural literacy. Specifically, among the sub-items, significant improvement was confirmed in the value and safety of agri-food, and agriculture and natural environment. Agricultural literacy began with the aim of the right development and realization of agricultural policies and, in the modern era, has been developed for a wide range of purposes: to wisely judge and cope with economic activities and policy decisions related to agriculture, and environmental issues of the whole society, by comprehensively analyzing knowledge about the functions and values of agriculture and rural areas, production, processing and distribution of agricultural products, agri-food and consumer life, agriculture and natural environment, etc, and sharing this knowledge with others (Chung, 2018). Agricultural literacy is something you should know as an upright democratic citizen, through which you can play a role as a smart consumer; those who have agricultural literacy are those who can synthesize and analyze basic information about agriculture and communicate with others (Chung, 2020). It is considered that the improvement of agricultural literacy through the farmer experience activities of adolescents residing in a self-reliance residence hall can help them not only in their job as a farmer, but also in their role as wise consumers. According to a study that measured the level of agricultural literacy of elementary school teachers, it was found that if the teachers' level of agricultural literacy is not high, their level of the items such as agricultural policies, and the value and safety of agricultural products is particularly very low (Chung, 2020). However, in this 
study, as the subjects were able to experience the value of agricultural products in the process of directly growing and harvesting crops, and the perception of the safety of agricultural products was gained while cultivating products in a eco-friendly manner, it is regarded that their improvement in the items such as the value and safety of agri-food, and agriculture and natural environment were significant, among the sub-items of agricultural literacy. No significant improvement in their agricultural literacy of agricultural production, processing and distribution of agricultural products can be attributed to the following results: the subjects could not experience direct processing by only visiting the processing room; and they also lacked understanding of the processing and distribution with only one-time direct experience of selling local food.

In addition, research on the change of hand function through agricultural experience has been insufficient. The Purdue Pegboard test began with the aim of selecting employees who can perform jobs that require manual dexterity and bimanual coordination, and has been used extensively (Shin, 2008), and this study found that by using the test the simple functions of the subjects'dominant hand and non-dominant hand were improved through the agricultural experience program. Such improvement is considered to have been influenced by the process of supporting cucumber and pumpkin vines using agricultural equipment while growing crops, as well as the experience of harvesting and packaging agricultural products.

Those who have gained basic awareness of agriculture and acquired first-hand experience of agriculture before adolescence have a high success rate of stably settling into farming activities (Oh and Kim, 2002), and for college students, the group with a high understanding of therapeutic agriculture showed high levels of willingness to engage in agriculture (Kang and Kim, 2017). It is considered that the agricultural experience program will enable youths living in self-reliance residence halls to enhance their understanding of agriculture as an occupation, and enable them to play a role as wise consumers by positively affecting improvements in their agricultural literacy and simple hand functions.

\section{Conclusion}

This study was conducted to improve understanding of agriculture as a profession through an agricultural experience program for adolescents residing in self-reliance residence halls and to determine the impact on independent living. The agricultural experience program consisted of orientation and watching videos on future agriculture, creating vegetable gardens, visiting the processing room, planting various crops, managing each crop, harvesting, selling local food, and recounting their impressions and engaging in discussions, and allowed them to gain a comprehensive experience regarding agricultural work from production to distribution. An evaluation survey of agricultural literacy was conducted to determine the subjects' understanding of agriculture, and a Purdue Pegboard test was performed to examine the effect of the agricultural experience program on their vocational ability. As a result, their agricultural literacy through the agricultural experience activities was found to be improved positively. Regarding hand function, the simple functions of the dominant hand and non-dominant hand were positively improved.

This study is significant in confirming the effects of the agricultural experience program on the improvement in agricultural literacy among youths in self-reliance residence halls, and also improvements in the simple hand functions of dominant and non-dominant hands. It is considered that it will help such youths to improve their understanding of agriculture as a profession and allow them to become wise consumers. In addition, this study also has significance in that it uncovered the possibility of using agricultural experience programs to assist adolescents in exploring career options.

The limitation of this study is that it is difficult to generalize the findings to all adolescents in self-reliance residence halls because it was conducted only on 11 subjects. In future studies, it is necessary to expand study regions and the number of participants from self-reliance residence halls, and conduct an agricultural experience program in which crop production, processing, and sales are subdivided to ascertain specific and objective results. 


\section{References}

Cho, J.Y. 2013. The relations between personality of male/female juvenile delinquents and vocationa interest type; focusing on committed juvenile. Master's thesis, Ewha Womans University, Seoul, Korea.

Cho, Y.j. 2017. Resistance, aspiration of freedom, and a destination of deviation: An ethnographic study of adolescents'experiences of independence in Youth Independence Shelter. Master's thesis, Korea National Open University. Seoul, Korea.

Choi, H.S., B.S. Kang, Y.S. Bang, and C.S. Song. 2016. Occupational therapy. Seoul. Gyechukmunwhasa.

Chung, N.Y. 2018. Comparative analysis on general agricultural education and agricultural literacy. J. Korean Pract. Arts Educ. (SKPAE) 24(3):1-30. https://doi.org/ 10.29113/skpaer.2018.24.3.001

Chung, N.Y. 2020. Asesment of and improvement plans for the agricultural literacy level of the elementary School teachers. J. Kor. Pract. Arts Educ. (SKPAE) 26(1): 89-104.

Heo, Y.J. and Jung C.Y. 2008. The development of thematic areas, sub areas and standards of agricultural literacy. J. Agric. Educ. Hum. Resour. Dev. 40(4):91-119. https://doi.org/10.23840/agehrd.2008. 40.4 .91

Jang, C., S.H. Park, K.H. Kim, M.J. Kim and J.Y. Lee. 2016. The effect of hand function build-up training on dexterity and grasp strength of hand. J. Kor. Soc. Integr. Med. 4(2):77-88. https://doi.org/10.15268/ksim.2016.4. 2.077

Jang, K.H. 2008. A study on the support for the independent living of adolescents in the residential care (Mainly about the adolescents who live in independent living facilities in Korea. Master's thesis, Kyung Hee University. Seoul, Korea.

Jeon, G.W. 2015. Agricultural literacy level of elementary students and related variable analysis. Master's thesis, Korea national University. Education. Chung-buk, Korea.

Jung, N.S., E.H. Choi and Y.G. Kim. 2019. Effects of debate education on the perception of agricultural and rural values-focused on the adolescent-. J. Korean Soc. Rural Plan. 25(3):103-114. https://doi.org/10.7851/Ksrp.2019. 25.3.103
Jung, N.S., Y.H. Lee, E.J. Kang and Y.G. Kim. 2016. Analysis of effect of urban agricultural experience activities to alleviate problem behaviors of adolescents. J. Agric. Ext. Community Dev. 23(3): 271-283. https://doi.org/10.12653/jecd.2016.23.3.0271

Kang, D.K. and H.S. Kim, 2017. College students acceptance of therapeutic agricultural activities and occupational intention about therapeutic agricultural professional. J. Rural Soc. 27(1):125-173. http://dx.doi.org/10.31894/ JRS.2017.06.27.1.95

Kim, S.K. 2019. A study of the effects of outside independent living experience program of the youth in child residential care. Korean J. Youth Stud. 26(9): 247-267. http://dx.doi.org/10.21509/KJYS.2019.09.26.9.247

Kwon, I.N., T.K. Kim, and M.S, Jeon. 2012. Study on reorganization of youth activity. Youth Facil. Environ. 10(3):3-15.

Lee, R.Y. 2019. The effects of career exploration group counseling program on career decision-making self-efficacy and career self-support preparation of shelter youths. Master's thesis, Mokpo national University, Muan, Korea.

Lowson, L. and Marcia M. 1995. Putting teens at the center: Maximizing public utility of urban open space through youth involvement in planning and employment. Child. Youth Environ. 12(2):209-221.

Oh, H.S. and J.J. Kim. 2002. The directions of supporting policy and education strategy for young agricultural workforce. J. Agric. Ext. Community Dev. 9(2):185-197.

Park, S.J., H.S. Chae, and D.Y. Hwang. 2019. An exploratory study on awareness change of participants in agricultural education -Focused on the agricultural career program for adolescents. J. Agric. Ext. Community Dev. 26(4):205-219. https://doi.org/10.12653/jecd.2019.26.4.0205

Shin, H.K. 2008. The recovery of hand function induced by EMG-triggered electrical stimulation in hemiplegic finger extensor. Korean J. Occup. Ther. 16(3):61-70.

Shin, H.S. 2013. A person-centered analysis of gender differences in profiles of adolescent aggression. Korean J. Youth Stud. 20(2):191-215.

Yun, W.S. 2011. The effect of structural characteristics and socioeconomic status of family on parenting and juvenile delinquency. Korean Criminol. Rev. 22(1):137-172. 